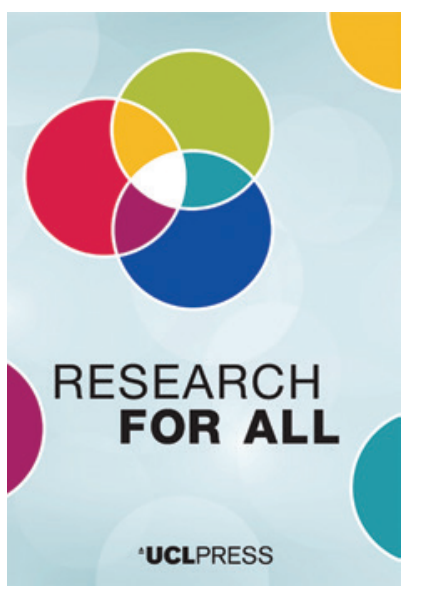

${ }^{ \pm}$CLPRESS

\section{RESEARCH FOR ALL}

The open-access journal for public engagement with research

ISSN 2399-8121 (Online)

Journal homepage:

https://www.uclpress.co.uk/pages/research-for-all

\title{
Public engagement with research: Citizens' views on motivations, barriers and support
}

\author{
Marion DreyeriD, Hannah Kosow (D), Anja BaueriD, Blagovesta ChonkovaiD, \\ Ventseslav KozareviD and Lada Timotijevic (iD
}

\section{How to cite this article}

Dreyer, M., Kosow, H., Bauer, A., Chonkova, B., Kozarev, V. and Timotijevic, L. (2021) 'Public engagement with research: Citizens' views on motivations, barriers and support'. Research for All, 5 (2), 302-19. https://doi.org/10.14324/RFA.05.2.08

Submission date: 14 August 2020

Acceptance date: 12 January 2021

Publication date: 21 September 2021

\section{Peer review}

This article has been peer-reviewed through the journal's standard double-blind peer review, where both the reviewers and authors are anonymized during review.

\section{Copyright}

(C) 2021 Dreyer, Kosow, Bauer, Chonkova, Kozarev and Timotijevic. This is an open-access article distributed under the terms of the Creative Commons Attribution Licence (CC BY) 4.0 https://creativecommons.org/licenses/by/4.0/, which permits unrestricted use, distribution and reproduction in any medium, provided the original authors and source are credited.

\section{Open access}

Research for All is a peer-reviewed open-access journal. 


\title{
Public engagement with research: Citizens' views on motivations, barriers and support
}

\author{
Marion Dreyer* - DIALOGIK, non-profit corporation for communication \\ and cooperation research, Germany \\ Hannah Kosow - University of Stuttgart, Germany \\ Anja Bauer - University of Klagenfurt, Austria \\ Blagovesta Chonkova - Applied Research and Communications Fund, \\ Bulgaria \\ Ventseslav Kozarev - Applied Research and Communications Fund, \\ Bulgaria \\ Lada Timotijevic - University of Surrey, UK
}

\begin{abstract}
Responsible research and innovation (RRI) approaches that have emerged in the past ten years point to the importance of engaging the public in dialogues about research. The different variants of RRI share the notion that societal actors, including citizens, need to work together - that is, engage in two-way communication during the research and innovation process - in order to better align both the process and its outcomes with the values, needs and expectations of society. Yet, sponsors and organizers of dialogues about research often face difficulties in recruiting sufficient numbers of participants or ensuring a sufficient level of diversity of participants. This paper asks what motivates or hinders individual citizens as members of the broader public to participate in such dialogues. It presents empirical findings of the European Union-funded project Promoting Societal Engagement Under the Terms of RRI (PROSO), which aimed to foster public engagement with research for RRI. PROSO used a quasi-experimental, qualitative approach directly involving citizens to address this question. The core of the innovative methodology were focus group discussions with European citizens about hypothetical opportunities to take part in dialogues about research. Three hypothetical scenarios of different dialogue formats (varied by whether they seek to inform the participants, consult or enable deeper collaboration on a scientific issue) were used as stimuli to explore the participants' willingness (motivations and perceived barriers) to engage with scientific research. Our findings show a preference towards dialogue formats that give citizens a more active role and a greater say in research policy or research funding. They further suggest that those who seek to broaden citizen participation in dialogues about research should consider the role of relevance, impact, trust, legitimacy, knowledge, and time and resources as factors that can motivate or discourage citizens to take part. Based on our findings, we discuss possibilities to promote citizen participation in dialogues about research as part of putting RRI into practice.
\end{abstract}

Keywords: public engagement with research, dialogues about research, citizen participation, responsible research and innovation, motivations for engagement, barriers to engagement 
Key messages

- European approaches of responsible research and innovation (RRI) postulate that societal actors, including citizens, play a role in research and innovation; those who invite citizens to engage through dialogues with research, however, often face difficulties in recruiting sufficient numbers of citizens.

- Many of the citizens we asked found it an attractive option to engage in dialogues about research that give them a more active role as consultants or collaborators, provided that certain conditions are met.

- The discussions among citizens confirm previous findings that personal interest, expected impact, and time and financial resources affect the willingness of citizens to take part in dialogues about research; they also show the importance of questions of trust, legitimacy and knowledge.

\section{Citizen views: An underexplored aspect of public engagement with research}

There is a widespread consensus in the literature that public engagement with research under responsible research and innovation (RRI) approaches extends beyond the unidirectional provision of research results from science to society. The different variants of RRI share the notion that societal actors, including citizens, need to work together that is, engage in two-way communication during the research and innovation process in order to better align both the process and its outcomes with the values, needs and expectations of society (for example, Sykes and Macnaghten, 2013; Stilgoe et al., 2014; Kuhlmann et al., 2015; Andersson et al., 2015a; Rask et al., 2018; for literature overviews see Burget et al., 2017; Bauer et al., 2016). Citizens are thus assigned an active role. They are invited to contribute their experiences and perspectives - for example, as participants in community-based research - and to raise questions and concerns about the direction of research and innovation - for example, as participants in dialogues about governing emerging technologies. Recently, the focus of RRI has shifted 'from policy to practice' (Owen and Pansera, 2019: 39), and the challenges of implementing $\mathrm{RRI}$ are gaining more attention. These challenges include 'unimpressive' response rates (Kleinman et al., 2011: 229) to recruitment of citizens to dialogues about research. Dialogue sponsors and organizers often face difficulties recruiting sufficient numbers of participants or ensuring a sufficient level of diversity of participants (for example, Bogner, 2015; Schütz et al., 2015).

If public engagement with research is to become the norm, public engagement scholars and practitioners need to gain better understanding of core issues affecting engagement, such as what are people's expectations of it, how they see their role in the field of research and innovation, and what are the factors that motivate or constrain their engagement. What European citizens personally think of two-way dialogues with researchers, or citizen dialogues to inform research policy or research funding, is a relatively underexplored aspect of citizen engagement. As social scientist Patrick Sturgis (2014: 40) put it, 'we know rather little about whether the public are as keen on participatory dialogue as those who advocate it as key to democratic governance'. The 2013 special Eurobarometer survey on Responsible Research and Innovation (RRI), Science and Technology gives a certain indication: overall, more than half (55 per cent) of the survey respondents believe that, when it comes to decisions made about science and technology, public dialogue is required (European Commission, 2013: 5). This desire for public dialogue by a majority of respondents does not tell us, however, 
that these respondents would actually be willing to get involved themselves, or what they would deem an attractive engagement opportunity.

In a report on desirable future practices and support strategies for public engagement with research and innovation, engagement scholars explain that there is important inquiry to be done into the motivations of participants to attend a deliberative event addressing research (Andersson et al., 2015b: 28). There is limited empirical research explicitly asking citizens about motivations for, and constraints on, engagement (one empirical study pertinent to the topics of this paper is by Kleinman et al. (2011) - the study concerns the situation in the United States, but it also has clear relevance for the European context), or specifically investigating motivations and constraints in regard to different dialogue-based formats (one pertinent study is Timotijevic and Raats, 2007).

This paper seeks to address the identified research need. It presents the main findings of an empirical study of the views of citizens about opportunities for participating in dialogues about research. Further, it provides a brief discussion of policies and practices that could foster such participation for RRI. The study seeks to contribute to exploring the challenges of mainstreaming citizen engagement with research, and possible ways to create more supportive conditions for engagement. The study was carried out in the European Union Horizon 2020 project Promoting Societal Engagement Under the Terms of RRI (PROSO), which was devoted to fostering public engagement with research for RRI. The research design focused on the following questions: What are the motivations and barriers for citizens to participate in dialogues about research? More specifically, what role does the format of the dialogue play in citizens' motivations and perceived barriers? Moreover, the research was designed to explore whether the research area and topic under discussion, and its levels of abstraction and familiarity, affect the motivations and barriers to participate.

\section{Our focus on public engagement with research}

There is a great and still growing diversity of approaches to opening up science and research (as a subset of science) ${ }^{1}$ to actors who are not routinely involved in such activities (Strasser et al., 2019). In this section, we explain our conceptualization of public engagement with research, and clarify our focus on formats of engagement and the participants' characteristics (Kosow et al., 2016; Chonkova et al., 2017).

First, by public engagement we refer to processes in which individual citizens are invited as members of the broader public. They are recruited as laypersons - that is, without specific knowledge on the issues at stake - and as unaffiliated citizens - that is, participating in a personal capacity and not as representatives of a particular group or organization (see Kahane et al., 2013, who show the analytical value of this distinction for public participation in political decision making).

Second, we conceptualize public engagement as such approaches, formats and activities that involve citizens as members of the broader public in organized dialogues about research and research policy or funding. These dialogues are initiated and organized by professional experts 'from outside' (for example, technology assessment experts), and are often part of publicly funded research. A recent publication noted that most public engagement projects in regard to science and research 'can be traced back to two main paradigms: the public participates either in a dialogue about science (governance) or in doing science in its diverse forms' (Schrögel and Kolleck, 2019: 78, emphasis in original; see also Kasperowski und Kullenberg, 2019: 5). The focus of our research has been on the first paradigm. We did not investigate the views of citizens in 
regard to doing or participating in research, best encapsulated in the citizen science paradigm, as well as in public and patient involvement in health and medical research. We explored citizens' views in regard to taking part in dialogues about new fields of research and articulating their questions, views, concerns and needs concerning these research fields. This is important to note, as we cannot, without further research, assume that the willingness of citizens to be involved in discussions about research is influenced by the same factors as their willingness to carry out research.

Third, we differentiate between three formats of dialogues about research, and refer to them as dialogue focused on information (science café), on consultation (citizen dialogue) and on collaboration (a citizen evaluation board - CEB). The main parameters to differentiate these formats are the functions of the dialogues, the related modes and degrees of interaction, and the proximity to decision making. The selection of parameters is informed by typologies in the literature to categorize different types of involvement of citizens in planning, policymaking, or research and innovation processes (see, for example, Arnstein, 1969; Rowe and Frewer, 2005; Irwin, 2014; Reed et al., 2018). The science café was included to provide a basis of comparison with dialogue formats that give citizens a more active role or a greater say in decision making on research. The science café was conceptualized as foremost a science communication event, but included also an element of interaction and dialogue, namely a citizens-scientists discussion section.

\section{The method: The 'national citizen panels'}

Our methodological approach was qualitative and had a quasi-experimental design which was applied across five European countries. We organized national citizen panels in Austria ( $N=18)$, Bulgaria $(N=18)$, Germany $(N=18)$, Portugal $(N=18)$ and the UK $(N=15)$. The main rationale of including different countries was to have, within the limits of the project's budget, a reasonably diverse basis to study European citizens' views on engagement with research. It was not the aim of the study to carry out a systematic cross-country comparison. Participants at the national level were recruited via recruitment agencies, based on quota sampling aiming to achieve diversity of participants in regard to the following criteria: gender, age, level of education and occupation (including unemployed and retired persons). As specified above, recruited citizens had no prior specific knowledge about the research topics and issues at stake, and they were unaffiliated. They were provided with a small stipend for their participation. EU, national and organizational ethical standards and requirements were strictly followed in the process, that is, organizers obtained ethics approval, as needed, and citizens signed forms of informed consent prior to their participation in the study.

In each country, the citizen panels met for a second time in order to further discuss and develop support options for citizen engagement with research, drawing upon the first series of citizen panels. In this paper, we set out only the design of the first citizen panels, which framed and directed the whole process. However, we present the findings on motivations, barriers and support options as a synthesis of results from both series of citizen panels.

\section{Procedure and materials of the main citizen panel meetings}

Upon arrival, citizens were allocated to three focus groups (five or six people per group), each discussing one specific topic. The research partners had jointly selected and defined these research topics to vary mainly in their levels of abstraction. The topics were: 'New foods to promote better health' (low level of abstraction, close 
to citizens' lives); 'Nanotechnology to clean up the environment' (medium level of abstraction, relatively high level of intuitive meaningfulness); and 'Synthetic biology for green energy' (high level of abstraction, very new technology with a comparably lower level of intuitive meaningfulness). Within each group, the citizens were provided with information materials, jointly designed by the research team, presenting each topic on a single page, including a description of the challenge, current research on the topic, possible benefits and drawbacks, and an example. Then, within each group, citizens were asked to reflect on three hypothetical scenarios of engagement, using fictitious letters of invitation to a science café, a citizen dialogue or a citizen evaluation board (see Figure 1). ${ }^{2}$

The three hypothetical dialogue formats introduced through fictitious letters of invitation, which the participants were considering, primarily varied by the format and impact - the way in which the citizens' input would influence decisions about research. All three hypothetical public engagement dialogues were presented as face-to-face events, and the invitations were issued by a non-commercial actor (see Table 1). We randomized the order in which the national groups discussed the three dialogue formats. In the last discussion session of each group, citizens were asked to compare the three formats and to share which they would be most willing to take part in.

\section{Figure 1: Discussing different dialogue formats in relation to different research topics - the focus group design (based on Chonkova et al., 2017: 8, with small modifications)}

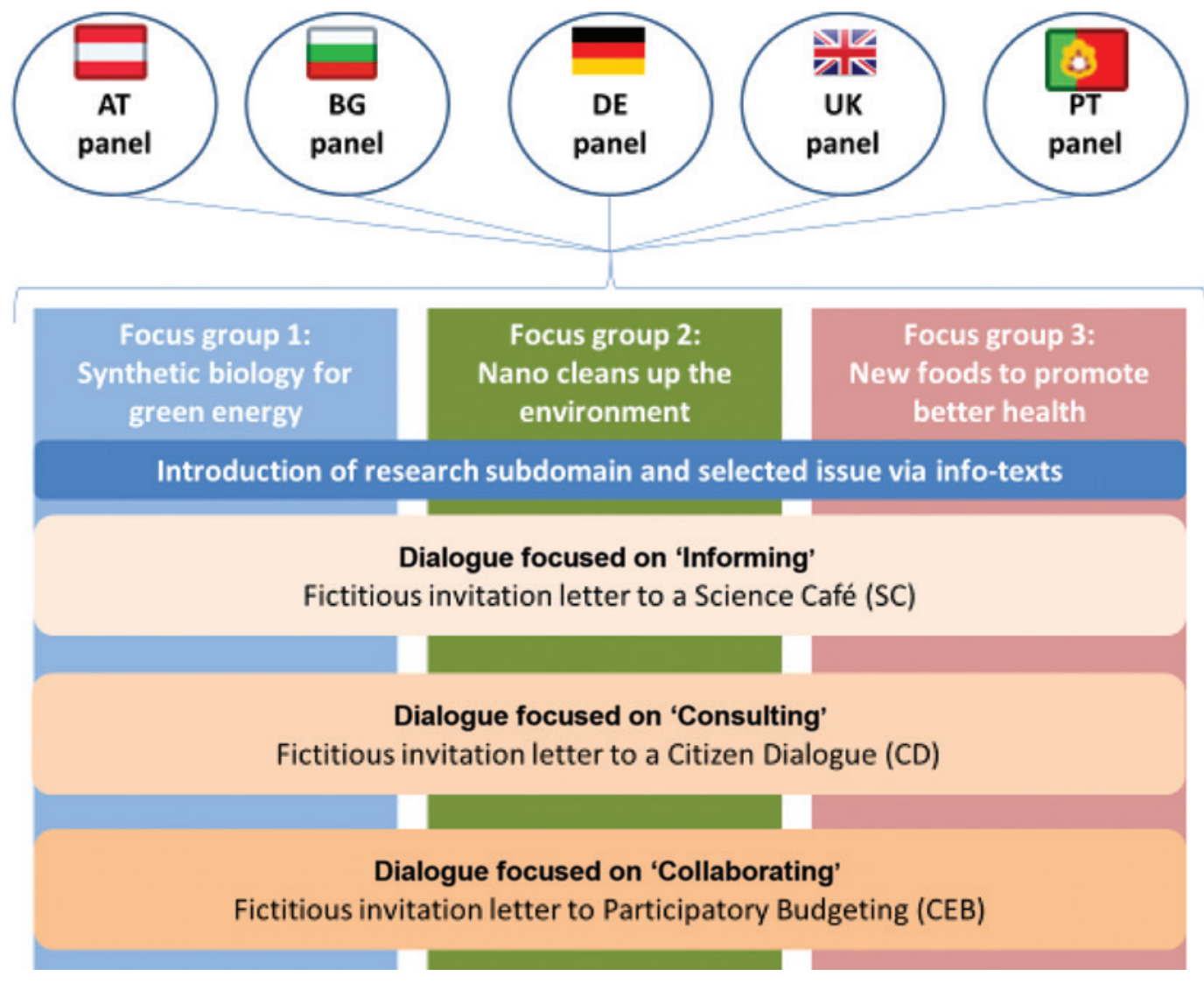


Table 1: Overview of the three dialogue formats, as elaborated in the fictitious invitation letters (drawing on Kosow et al., 2016: 16-17)

\begin{tabular}{|c|c|c|c|}
\hline & Science café & Citizen dialogue & $\begin{array}{l}\text { Citizen evaluation } \\
\text { board - CEB } \\
\text { (participatory } \\
\text { budgeting) }\end{array}$ \\
\hline Initiating actor & $\begin{array}{l}\text { Local Science Café } \\
\text { Association (NGO) }\end{array}$ & Ministry of Research & $\begin{array}{l}\text { National Research } \\
\text { Foundation (NRF) }\end{array}$ \\
\hline $\begin{array}{l}\text { Primary aim of } \\
\text { the dialogue }\end{array}$ & $\begin{array}{l}\text { To inform citizens } \\
\text { about new science } \\
\text { and research }\end{array}$ & $\begin{array}{l}\text { To consult citizens on a } \\
\text { specific research domain and } \\
\text { associated issues in order to } \\
\text { inform research policy }\end{array}$ & $\begin{array}{l}\text { To collaborate with } \\
\text { citizens in decision } \\
\text { making on research } \\
\text { funding }\end{array}$ \\
\hline $\begin{array}{l}\text { Main task for } \\
\text { the citizens }\end{array}$ & $\begin{array}{l}\text { 'You will have the } \\
\text { opportunity to } \\
\text { learn and discuss } \\
\text { about a new } \\
\text { research field.' }\end{array}$ & $\begin{array}{l}\text { 'With other citizens, you will } \\
\text { discuss your views, concerns, } \\
\text { expectations and hopes for } \\
\text { this research area. Focus will } \\
\text { be on your personal opinion } \\
\text { on the issue.' }\end{array}$ & $\begin{array}{l}\text { 'As a member of } \\
\text { the CEB, you will } \\
\text { provide the NRF with } \\
\text { recommendations } \\
\text { regarding the societal } \\
\text { relevance and concerns } \\
\text { of research to be } \\
\text { funded by the NRF.' }\end{array}$ \\
\hline $\begin{array}{l}\text { (Potential) use } \\
\text { of results }\end{array}$ & Not specified & $\begin{array}{l}\text { 'Your views will provide } \\
\text { the Ministry of Research } \\
\text { with valuable information } \\
\text { about whether and how } \\
\text { research in this field may } \\
\text { be an appropriate option } \\
\text { to answer the specified } \\
\text { challenge.' }\end{array}$ & $\begin{array}{l}\text { 'The NRF will include } \\
\text { the recommendations } \\
\text { of the CEB as important } \\
\text { information in their final } \\
\text { assessment process. } \\
\text { Your perspectives } \\
\text { will complement the } \\
\text { assessment of the } \\
\text { research proposals by } \\
\text { other researchers (a } \\
\text { process called "peer } \\
\text { review").' }\end{array}$ \\
\hline $\begin{array}{l}\text { Degree of } \\
\text { responsibility } \\
\text { assigned to } \\
\text { citizens }\end{array}$ & $\begin{array}{l}\text { No responsibility } \\
\text { ascribed to, or } \\
\text { taken on by, } \\
\text { citizens }\end{array}$ & $\begin{array}{l}\text { Weak responsibility ascribed } \\
\text { to, and taken on by, citizens }\end{array}$ & $\begin{array}{l}\text { Some co-responsibility } \\
\text { - but no strong } \\
\text { responsibility, as further } \\
\text { assessment of research } \\
\text { proposals is done by } \\
\text { expert peer review, and } \\
\text { the final decision about } \\
\text { funding lies with the } \\
\text { NRF as the research } \\
\text { funding organization }\end{array}$ \\
\hline $\begin{array}{l}\text { Selection of } \\
\text { citizens }\end{array}$ & Self-selection & Quota sampling & Quota sampling \\
\hline Required time & $1.5-2$ hours & One day & $\begin{array}{l}\text { Over two years, two } \\
\text { weekends each year }\end{array}$ \\
\hline $\begin{array}{l}\text { Monetary } \\
\text { compensation }\end{array}$ & None & $\begin{array}{l}\text { Stipend according to } \\
\text { local rates (symbolic } \\
\text { compensation, not a salary) }\end{array}$ & $\begin{array}{l}\text { Stipend according to } \\
\text { local rates (symbolic } \\
\text { compensation, not a } \\
\text { salary) }\end{array}$ \\
\hline
\end{tabular}

\section{Data collection and analysis}

Focus groups were facilitated by group moderators, who were either members of the research team or external facilitators, dependent upon the staff resources of the 
research partners responsible for the citizen panels in their country. Citizens in all countries and across groups responded to the same set of predefined questions. The questions had been drafted in an iterative process by the research team, and recorded in a focus group manual for use by the national partners in the citizen panels (Chonkova et al., 2016). Note-takers used a standardized observation protocol to document the discussions, with minimal interpretation. The observers' notes were the main empirical data. In four of the five countries, the discussions were also audio-recorded, and the recordings were used to review and validate the observation notes. In one country, audio-recording was not used because of concerns from earlier experiences that recording can be intimidating to citizen participants. National summary reports were produced in English following a standardized template. The reports were collected and further analysed via NVivo 10 (Bazeley and Jackson, 2013). Descriptive coding (Saldaña, 2015) was carried out to determine emerging themes and their frequency of appearance in order to identify the main themes. Group discussions were imported into NVivo 10 as external text documents (cases), and were assigned three attributes (providing the equivalent of categorical independent variables): specific research topic and level of abstraction, dialogue format, and country. Data were then analysed thematically (Braun and Clarke, 2006) and cross-tabulated for each attribute to examine if there were any distinct trends in citizens' views related to these categories. In the following presentation of results, we provide selected quotations from the citizens to illustrate prominent themes concerning motivations and barriers. The quotations from Austria, Bulgaria, Germany and Portugal were translated into English by the research team.

\section{Results: Citizens' willingness to engage and their views on barriers}

In this section, we present the main empirical findings across the national citizen panel meetings. We first set out citizens' overall preferences in regard to the three dialogue formats. Then we describe six engagement barriers that we deduced from the analysis of the citizens' discussions, and provide examples of what citizens considered as promising ways to lower these barriers. According to our findings, the six barriers for citizens to engage in dialogues about research have relevance across all countries in which the citizen panel meetings took place, even though the strength of each barrier may vary between countries.

\section{Preferences for dialogues giving citizens a more active role}

The analysis of the citizen panels reveals a preference towards formats that give citizens a more active role and a greater say in research policy or research funding. Both the CEBs (citizens in the role of collaborators) and the citizen dialogues (citizens as consultants) were seen as attractive and valuable options in all five countries. Both would allow for active, deliberative participation, and aimed to make a difference in research policy or funding policy, while also offering an opportunity to learn about new research. In regard to the CEBs, it was deemed important that this format had a clear democratic value (providing citizens with a role in distributing tax money), that it was likely to have a specific impact, and that it offered the participating citizens the possibility to achieve a deeper understanding about a particular research area in direct interaction with researchers. Overall, the CEB was viewed as the preferred dialogue format, if the intention was to enact real change in the science-society relationship. 
At the same time, the citizens saw an important role for all three dialogue formats in establishing a sound science-society relationship. Several citizens appreciated science communication events (citizens foremost being receivers of information) as good opportunities to pick up on recent developments in science and research. Science cafés were considered informal, hardly demanding, comparatively relaxed and, therefore, interesting to a wider audience. Many citizens were in favour of complementing more traditional formats such as science cafés with digital infrastructures (for example, a 'Research YouTube') that would support continuous, broader and more self-determined learning about research.

\section{Six barriers to engagement}

While most citizens expressed a preference for dialogue formats that give them an active role in research policy or governance, the group discussions made clear that, nevertheless, there are several possible constraints to seizing such participation opportunities. We identified six factors as the main barriers to citizen participation in dialogues about research: lack of relevance, lack of impact, lack of trust, lack of legitimacy, lack of knowledge, and lack of time and financial resources. According to our findings, the barriers are not format-specific. It is clear, however, that their strength varies with the particular design and context of a specific dialogue event or process.

\section{Lack of relevance of the research area or topic}

The citizens made clear that, in their view, highly technical research areas and topics with low media coverage can deter citizens from participating in a dialogue about research. They found a participation opportunity less attractive if they considered the research area or topic as not 'burning', and therefore of no clear societal relevance, or if they had no personal interest in the area or topic because it was not relevant to citizens' own interests, concerns, goals or everyday life. As one UK citizen stated: 'If the topic isn't interesting, even the money [that was hypothetically offered] would not help to encourage their [citizens'] participation.'

As expected, most of the participants in the national panels perceived the food and health topics as more relevant to their lives and societies than the other two research topics, and they considered these issues as more attractive for participation. Both nanotechnology and synthetic biology were equally perceived as quite abstract and detached from their everyday lives. A Portuguese citizen quite clearly refused the invitation to the science café, exclaiming: 'Nanotechnology, what is it? I would not read anything more.' Therefore, citizens underlined the importance of awareness-raising activities, and advocated that the media play a more active role by broadcasting scientific achievements and their (possible) application in the everyday lives of people. Further, citizens thought it essential that scientists are able to present research topics in an understandable way and to demonstrate their relevance (if any) to citizens' lives now or in the future.

\section{Lack of impact}

Citizens named prospects of impact as a prominent motivating factor for participation, and they therefore favoured dialogue formats in which citizens have a consultative or collaborative role. While internal incentives, such as being able to learn something new and develop new skills, might be considered a sufficient motivation by some citizens, other citizens could be discouraged from taking part if they did not expect concrete impact on research processes, policies or outcomes. On these grounds, most 
participants in the national citizen panels favoured the CEB dialogue format. The CEB was explicitly and credibly part of a decision-making process, and therefore most likely to have impact. Several citizens were sceptical of dialogues aimed at consultation or collaboration without a clear link to decision making. Reacting to the invitation for the citizen dialogue, one Austrian citizen criticized: 'The text does not say what the Ministry will do with the results. I would hesitate to participate if I didn't know what they use it for.'

Compared with powerful lobbying groups, political interests and expert opinions, citizens considered small numbers of dialogue participants (as foreseen in the citizen dialogue and CEB formats) as inadequate to produce any impact on research and policymaking processes. Therefore, they supported the idea of combining face-toface deliberative dialogues with online engagement activities, such as broad opinion surveys, in order to include a greater number of voices in citizen consultations. Further, many citizens strongly suggested that sponsors and organizers of dialogue events should provide feedback to the participating citizens about how the results of the specific dialogue were used, and whether and why citizens' input or recommendations were (or were not) taken up or implemented.

\section{Lack of trust in organizers, scientists and/or policymakers}

A range of participants in the national citizen panels lacked trust in the agendas of sponsors and organizers of dialogue processes. They suspected that dialogue initiatives may be instrumentalized by policymakers to justify decisions already taken, as the following statement by a Portuguese citizen illustrates: 'Participation just to participate is not worth it; participation serves to legitimize the views of those who are normally already involved; participation always hides suspicious interests.'

Scepticism and mistrust were also manifest among the panel participants regarding the motivations of scientists pursuing certain new technological developments. Participants referred to the increased role of economic interests in science to the detriment of societal interests and addressing societal needs. Some also expressed distrust towards information provided to the general public in regard to new scientific developments. The panel participants strongly supported the idea that it needs to become good practice in dialogues about research that the whole process - its rationale, aims, outcomes and impact - are made transparent and disseminated to the wider public.

\section{Lack of legitimacy}

Several participants found that dialogues involving only small groups of citizens might not only be ignored by decision makers, but might also lack input legitimacy, which is derived from the procedural aspects of engagement, to represent societal interests, needs and concerns. They explained that it could discourage them from taking part in such dialogues, if they deemed the participating group of citizens to be not sufficiently diverse and to be clearly dominated by the urban middle classes. Some citizens underlined that small groups of citizens were not sufficiently legitimized to 'speak on behalf of society' or to 'decide on behalf of the whole country', and that they themselves would not want to take responsibility for results that did not reflect all relevant perspectives of the wider public. One German citizen summarized this often raised concern: 'For me, that's not engagement ... There have to be more people involved.' Another citizen added: 'That's only one per Bundesland [federal state], plus four others.' 
Some citizens expressed the belief that policymakers would take into account citizens' views only if a significant, if not statistically representative, number of citizens were involved. These were other reasons why citizens advised the inclusion of a broader range of voices in citizen consultations or collaborations by integrating offline and online citizen engagement.

There were also participants who had fundamental doubts as to whether the wider public should have a say about research. The main reason given was that the 'ordinary citizen' lacks relevant knowledge, views and interests. In this view, scientifically trained professionals were the only legitimate participants in research-related activities. Some citizens emphasized that they personally would find the idea of taking part in a citizen dialogue or a CEB, as described in the fictitious invitation letters, very exciting and attractive. However, they could hardly imagine such processes happening in their countries, where citizen engagement in research was likely to be considered a rather strange idea. In this regard, some participants supported the idea that professionals of the research system and research policymakers should specify more clearly the contributions that the wider public can make to research, and thereby promote a more positive view of the role of citizens in science and research. There was also some support for the idea that citizen engagement with research should be included in school curricula.

\section{Lack of knowledge}

Most participants preferred formats that give citizens a more active role in research. On the other hand, it was a common concern among the participants that they might lack the knowledge about a given research area or topic to take part in such dialogue formats. This was mentioned especially in regard to the CEBs, as this statement by an Austrian citizen illustrates: 'I don't think that I know enough to take responsibility. The problem is when you reject something [a research proposal] that could be really important and interesting, only because you don't like it for some reason. I feel I am not competent enough.'

Some participants were particularly concerned that the participation of illinformed or unknowledgeable citizens would lead to results and decisions of poor quality. Many panel participants thought it essential that citizens invited to take part in a dialogue as consultants or collaborators are assured that they will receive all the content- and procedure-related information that they need to take part in the dialogue in a meaningful manner. In their view, sponsors and organizers can address the knowledge issue, at least to some extent, by combining dialogue and information in the design of a citizen engagement format. Some participants argued that it was also important to include scientists who have the communication skills and ability to excite and inspire citizens about research topics, and to explain these in accessible terms. In this regard, scientists would need more training. Other participants shared the view that it is very difficult for laypersons to interact with scientists. They felt that citizens may shy away from more interactive participation because they have a (too) respectful or even slightly fearful attitude towards science, and assume that scientists are not really interested in being understood by laypeople.

\section{Lack of time and financial resources}

Participants addressed a lack of time and financial resources, especially in regard to issues of inclusiveness and diversity. An Austrian citizen commented on the time demanded by the Evaluation Board: 'For people who work, the event is too long. 
People working full time, maybe having a family, cannot afford to spend a whole day of their weekend at this even.'

Citizens widely agreed that the inclusion of citizens from different socio-economic backgrounds in research-related and time-consuming consultations and collaborations requires that at least participants' costs are compensated (travel, accommodation, food, possibly also care facilities for children or elderly people). Several participants demanded in addition a stipend for time-consuming and demanding activities such as the CEB. In response, other participants expressed the concern that some citizens might only be attracted by the financial benefit, and that 'professional participants' would emerge if the monetary compensation was too substantial. Still others noted that for them a stipend would feel like an insult, and would discourage them from participating. Nevertheless, many participants found it reasonable to explore in larger debates at national level innovative mechanisms to foster citizen participation in research-related consultations and collaborations, such as regulatory mechanisms guaranteeing a limited number of compensated days off work for participation activities. A Portuguese citizen demanded: 'Why on the weekend? Civic work such as this one should take place in the working hours. This is clearly a civic duty issue.'

\section{Synthesis of findings and discussion}

Our findings from the national citizen panels confirm, complement and add to insights reported in the existing literature. They suggest that there is a significant number of European citizens who consider participation in dialogues about research an attractive option, particularly when the dialogues have a clear link to decision making on research. This finding is in line with the results of the 2013 special Eurobarometer (European Commission, 2013). Further, our findings confirm previous insights and reflections that general positive attitudes towards dialogues about research should not be expected to translate simply into a personal willingness to participate in a concrete case, and that a whole host of factors determine the likelihood of engagement in dialogues about research for any particular individual.

\section{Relevance, impact, time and financial resources}

We found that personal interest, expected impact, and time and financial resources are factors that can affect citizens' willingness to engage. These factors have also been described in earlier scholarly contributions about public engagement in dialogues about research. The willingness to participate is likely to be higher if participation opportunities link with the personal interests of citizens. Examples of a personal interest are an individual interest in learning about research issues that affect one's own life, concerns about newly emerging technologies, or a more structural interest in contributing to societal debates on 'burning' research issues that are dealt with prominently in wider public debates and by the mass media (see Kleinman et al., 2011; Timotijevic and Raats, 2007). Personal interest can also result from the expected impact of a dialogue exercise, for example, on community life or research policies (see Kleinman et al., 2011; Wilkinson et al., 2012). Expected impact can also work as an incentive to participate if citizens do not have a personal interest in a specific outcome of a dialogue process. Citizens may not want to invest valuable time in a consultation-focused dialogue without a concrete outcome and impact. Citizens are laypersons in the sense that they are not research professionals; therefore, they have to reallocate leisure time or time at their workplace to take part in dialogues about research (see Lidskog, 2008: 83; Timotijevic and Raats, 2007). Our results suggest 
that citizens expect that their investment of time and resources in research-related consultations or collaborations is recognized and acknowledged. This includes that at least the costs incurred by participation are compensated (see Kleinman et al., 2011: 13). Compensation is a form of acknowledgement, but it is also a way to react to the unequal distribution of time and resources in society, which hinders equal participation by all (Castell et al., 2014).

\section{Trust, legitimacy and knowledge}

The findings from the national citizen panels add to existing insights by indicating that willingness to engage is affected also by aspects of trust, legitimacy and knowledge. The willingness to participate is likely to be higher if citizens have reason to trust the agendas of policymakers or funding authorities as sponsors of dialogues, and the agendas of scientists and researchers who take part as experts in dialogues. It is an empirical question whether, in a specific case, such expectations are justified or not. Concerns that public engagement with research is at risk of being instrumentalized to enforce particular interests have been expressed for some time in the existing literature (see, for example, Stilgoe et al., 2014). Our findings suggest further that citizens may be more inclined to participate if they have reasons to expect that they will be part of a diverse group of participants, which feeds a great variety of views, concerns and interests into a consultation or collaboration process. Again, it is an empirical question whether or not such expectations are justified in a specific case. Previous research has found that participants in dialogues about research tend to have higher incomes and to be more educated (Kleinman et al., 2011; Powell et al., 2011; Sturgis, 2014; Castell et al., 2014: 8; Rowe et al., 2008). Kleinman et al. (2011: 3) have pointed out that higher incomes, often connected with higher education, tend to translate into additional discretionary time. Further, the disproportionate representation of better-educated citizens has been related to skills-based obstacles. The emphasis on two-way dialogues and expressing one's own views to others is assumed to privilege those citizens trained in such interactional techniques (see Davies, 2014, with reference to Sanders, 1997). Citizens may also be more willing to participate, if they think that 'ordinary laypeople', that is, individuals without a scientific position or expertise, can make valuable contributions to research-related activities. At the same time, our findings strongly suggest that citizens are more inclined to take part in a dialogue about research when they have reasons to expect that they will be provided with all the process- and content-related information required to participate in a meaningful manner. The importance of information material as a supportive condition in citizen deliberations has been highlighted in the relevant literature (for example, Bächtiger and Wyss, 2013).

\section{Limitations of our data}

There are limitations to the data collected from the citizen panel meetings. First, our sample of citizens was subject to a selection bias because it exclusively involved people who had chosen to participate in the research project. Hence, they are already more inclined to favour public engagement. We provided the participants with a small stipend for their participation. This might have reduced this bias, as it provided citizens with additional motivation besides their willingness or interest to take part in research (or with an alternative motivation). Second, due to limited resources, we explored the views of citizens on the different dialogue formats using a hypothetical decision situation. We think this approach was helpful to gain valuable insights into citizens' views of what makes participation in a dialogue about research attractive, and what 
does not. It is clear, however, that the use of fictitious invitation letters cannot reveal genuine reactions and criteria for decision making in real-life situations. We also need to be cautious not to overinterpret the data because citizens did not speak exclusively about their personal views, motivations and constraints in the focus group discussions, but also sometimes made assumptions about other citizens or the wider public. Third, the fact that our analysis was based on a rather small data set left us with only vague indications of nationally relevant trends in citizens' views of dialogues about research, and we feel that the sample sizes are too small to generalize. For this reason, we do not give greater attention in this paper to the comparison of citizens' views between the different countries.

Across all national citizen panels, we found an overall preference towards formats that give citizens a more active role and greater say, and references to the six barriers. We cannot derive from the empirical material how exactly national contexts, and what types of national contexts (for example, civic culture and history), may influence citizens' preferences and views about the relative strength or weakness of barriers and motivations; this would require larger country data sets. However, we can use the material to formulate some suggestions for policy and practice options to support citizen participation in dialogues about research. (See Dreyer et al. (2018) for options to support public engagement with research more generally.)

\section{Implications for policy and practice for responsible research and innovation}

We now present several policy and practice options to deal with the identified barriers, and to foster dialogue-based public engagement in the European research systems for better serving the public, as targeted by RRI approaches. By policy and practice options, we understand measures and activities that create more favourable conditions for citizen participation in dialogues about publicly funded research as part of putting RRI into practice. They concern various actors of the research and innovation systems, including research policymakers, research funding organizations, public and private research organizations, and (other) engagement-performing organizations.

In the short term, we see potential to motivate a larger number of citizens through a more consequential implementation of process design, and recruitment strategies that have come to be widely recognized as good practice for dialoguebased public engagement with research. Facing possible barriers of scarce resources, limited knowledge, lack of legitimacy of small groups, and scepticism of the motivations of scientific experts, sponsors and organizers of dialogues about research are well advised to consider:

(1) designing a dialogue process that systematically combines argumentative exchange with provision of scientific-technical information, and asking the participants to select or co-select the scientific experts

(2) integrating face-to-face dialogue formats with online engagement tools

(3) clearly indicating how the dialogue process links to and informs policymaking or decision-making processes, or to point out other concrete ways in which impact can be expected

(4) compensating the citizens for the direct costs incurred by participation

(5) ensuring full transparency at the point of recruitment in regard to these design aspects, and more generally in regard to the roles and responsibilities of all actors involved, including the concrete contributions that the citizens are expected to make and what makes them valuable contributors 
(6) avoiding framings that may create the impression that citizens are asked 'to speak for society'; engagement in a joint production of reflected views 'from within society' could be an alternative framing.

In the medium term, EU and national research-funding policies and programmes under RRI may be created, adapted or strengthened to initiate dialogues about research that deal with issues in which citizens are likely to take a personal interest. One promising practice example is funding of dialogue processes that provide opportunities for citizens to co-shape visions of the future, and which serve participatory agenda setting. Another, still underdeveloped option, involves dialogue processes - for instance, as part of so-called real-world laboratories - that address the local and regional scale, and concern matters of more direct relevance to the everyday life of most citizens or particular groups of citizens who are, for instance, in the same age group or live in the same environment. It is already a widespread practice that citizens are paid a small stipend to acknowledge their efforts. It is important that these costs are considered as eligible by funding organizations. Dialogues about research in which citizens from different socio-economic backgrounds, including less privileged groups, take part and are actively involved in the interactions can be part of future success stories of RRI. Research can be funded to explore mechanisms of exclusion and inclusion to inform efforts to mainstream public engagement with research. New infrastructures and networks - for example, for exchanges on good practice in dialogues about research at EU and national levels - may add to increasing knowledge and capabilities for public engagement with research among all relevant actors.

Finally, fostering dialogues about research under RRI can also be understood as a long-term project to be supported by more fundamental changes in European research systems and cultures. Research organizations could establish competencies to engage with citizens - for example, communicative skills - and to support units within their organizations. Engagement with research could also be embedded more widely into education systems to systematically raise interest in research and innovation and scientific literacy from an early age. Further, the role of science journalism is crucial, not only in raising awareness about scientific developments and promoting informed scientific debates, but also in exerting pressure on policymakers to publicly deal with results of dialogue initiatives. One way to strengthen science journalism is to make it an integral part of the education of journalists at universities. Another way is to establish structures for dialogue between policy, science and journalists. In order to develop a culture for public engagement with research, policymakers and governmental agencies could encourage changes in how scientific reputation is measured, and commit to dialogues about research through national strategies or guidelines.

\section{Conclusion}

In this paper, we have presented findings from a series of focus groups organized across several European countries. Our approach and findings add to the still limited empirical research on European citizens' views about barriers and incentives to participate in different dialogue formats concerned with research. While the data were collected across five countries, the focus of our study was on commonalities, rather than differences. In the future, studies should be devised to systematically explore the country- and culture-specific factors (such as openness of the science system to the wider public, or civic engagement culture and tradition). These may lead to a more differentiated picture of citizen views in different countries, and of respective policy 
options to encourage engagement with research in different national contexts. This paper offers a couple of generic policy and practice options to overcome barriers that are transnational, rather than specific to particular countries. We recommend that governments, policymakers, funding agencies and engagement-performing organizations in Europe consider these options as possible ways to put engagement policy of RRI into practice.

\section{Acknowledgements and disclaimer}

This article is an outcome of the project Promoting Societal Engagement Under the Terms of RRI (PROSO). The PROSO project has received funding from the European Union's Horizon 2020 research and innovation programme under Grant Agreement No. 665947. The contents of the article reflect only the authors' views. The Research Executive Agency (REA) of the European Commission is not responsible for any use that may be made of the information that the publication contains. We owe a considerable debt of gratitude to the citizens who gave their time to commit themselves to our work by participating in the national citizen panels, and to the reviewers for their valuable comments on an earlier draft of this paper.

\section{Notes}

1 In this paper, 'research' refers to scientific research as a systematic way of gathering data and producing knowledge.

2 The UK invitation letters are available at www.proso-project.eu/wp-content/uploads/ materials_citizen_panel_first_meeting_united_kingdom.pdf. All the invitation letters, translated and adapted to the respective national contexts, are available at www. proso-project.eu/publications, under the heading 'Deliverable D4.1: Methodology Citizen Panels'.

\section{Notes on the contributors}

Marion Dreyer is a social scientist and Deputy Scientific Director of DIALOGIK, a non-profit research corporation for investigating and developing communication and participation processes in regard to policy planning and conflict management. Marion has over twenty years' experience of research on the opportunities and challenges of engagement of stakeholders and the wider public in new science and technology developments and in tackling grand societal challenges.

Hannah Kosow, a social scientist by training, is a postdoctoral research associate at the University of Stuttgart - Research Center for Interdisciplinary Risk and Innovation Studies (ZIRIUS), Germany. Her research focuses on inter- and transdisciplinary approaches (for example, citizen and stakeholder engagement, qualitative systems analysis, scenario analysis) to explore complex interrelations between society, technology and the environment.

Anja Bauer is a political scientist by training, and is currently an assistant professor in the Department of Science and Technology Studies at the University of Klagenfurt, Austria. She researches and teaches in the areas of environmental sustainability and technology governance, with a special interest in the role of expertise, anticipation and participation in policymaking. 
Blagovesta Chonkova is a social scientist working as a project manager at the Applied Research and Communications Fund, Bulgaria. She has more than eight years of professional experience doing research on topics related to responsible research and innovation, and public engagement in science, technology and innovation processes and policymaking, social innovation and innovation in the public sector.

Ventseslav Kozarev is the former Programme Manager for Science, Technology and Innovation Policy at the Bulgaria-based Applied Research and Communications Fund (2017-20). He has ten years of research and innovation management experience, with a strong emphasis on issues of science and technology, science communication and knowledge-informed policy advice. Ventseslav holds a master's of public policy degree from the University of Minnesota, USA, and has specialized in technology assessment at NOVA University Lisbon, Portugal.

Lada Timotijevic is an associate professor/principal research fellow in the School of Psychology, University of Surrey, UK. She is a social psychologist with over sixty publications in the areas of risk communication and management, public/stakeholder engagement and behaviour change. Her research portfolio includes governance and ethics in public health nutrition and digital health, where she researched user needs and socio-ethical implications of digital technologies, with a particular view to developing appropriate ethical governance regimes.

\section{References}

Andersson, E., Bussu, S. and Davis, H. (eds) (2015a) 'Science, society and engagement: An e-anthology' (Deliverable 2.2 of the EU-funded Engage2020 project, GA No. 612281). Accessed 12 January 2021. http://engage2020.eu/media/Engage2020_withVideo.pdf.

Andersson, E., Bussu, S., Davis, H., Mulder, H., Klüver, L., Jørgensen, M.L., Nierling. L., Kuhn, R., Kozarev, V. and Damianova, Z. (2015b) 'What the future holds for societal engagement' (Deliverable 4.2 of the EU-funded Engage2020 project, GA No. 612281). Accessed 12 January 2021. http://engage2020.eu/media/D4.2-Future-Engagement.pdf.

Arnstein, S.R. (1969) 'A ladder of citizen participation'. Journal of the American Institute of Planners, 35 (4), 216-24. https://doi.org/10.1080/01944366908977225.

Bächtiger, A. and Wyss, D. (2013) 'Empirische Deliberationsforschung - eine systematische Übersicht'. Zeitschrift für vergleichende Politikwissenschaft, 7 (2), 155-81. Accessed 3 June 2021. http://www.andre-baechtiger.ch/tl_files/baechtiger/pdf/Empirische\%20Deliberationsforschung. pdf.

Bauer, A., Bogner, A. and Fuchs, D. (2016) 'Societal engagement under the terms of RRI'. (Deliverable 2.2 of the EU-funded PROSO project, GA No. 665947). Accessed 12 January 2021. www.proso-project.eu/wp-content/uploads/proso_d2.2_societal_engagement.pdf.

Bazeley, P. and Jackson, K. (eds) (2013) Qualitative Data Analysis with NVivo. 2nd ed. London: Sage.

Bogner, A. (2015) 'From invited participation to blue sky engagement'. In C. Scherz, T. Michalek, L. Hennen, L. Hebáková, J. Hahn and S.B. Seitz (eds), The Next Horizon of Technology Assessment. Proceedings from the PACITA 2015 Conference in Berlin. Prague: Technology Centre ASCR, 127-31. Accessed 12 January 2021. https://pacita.strast.cz/files/Publikace/Proceedings-Berlinv3.2-FINAL_3.pdf.

Braun, V. and Clarke, V. (2006) 'Using thematic analysis in psychology'. Qualitative Research in Psychology, 3 (2), 77-101. https://doi.org/10.1191/1478088706qp063oa.

Burget, M., Bardone, E. and Pedaste, M. (2017) 'Definitions and conceptual dimensions of responsible research and innovation: A literature review'. Science and Engineering Ethics, 23 (1), 1-19. https://doi.org/10.1007/s11948-016-9782-1.

Castell, S., Charlton, A., Clemence, M., Pettigrew, N., Pope, S., Quigley, A., Shah, J.N. and Silman, T. (2014) Public Attitudes to Science 2014: Main report. London: Ipsos MORI Social Research Institute. Accessed 12 January 2021. www.ipsos.com/sites/default/files/migrations/en-uk/files/ Assets/Docs/Polls/pas-2014-main-report.pdf. 
Chonkova, B., Kozarev, V., Asenova, D., Kosow, H. and Dreyer, M. (2016) Manual - Citizen panel meetings (Guidance paper of the EU-funded PROSO project, Grant Agreement No. 665947). Accessed 12 January 2021. www.proso-project.eu/wp-content/uploads/wp4_manual_citizen_panels.pdf.

Chonkova, B., Asenova, D. and Ventseslav, K. (2017) Synthesis Report on Citizens' Views of Engagement in Research-Related Activities (Deliverable 4.3 of the EU-funded PROSO project, Grant Agreement No. 665947). Accessed 12 January 2021. www.proso-project.eu/wp-content/ uploads/proso_d4.3_citizen_panels_synthesis.pdf.

Davies, S.R. (2014) 'Knowing and loving: Public engagement beyond discourse'. Science \& Technology Studies, 27 (3), 90-110. https://doi.org/10.23987/sts.55316.

Dreyer, M., Kosow, H. and Dratsdrummer, F. (eds) (2018) Engaging Society for Responsible Research and Innovation: Lowering barriers - innovating policies and practices. A support tool for promoting engagement of citizens and third sector actors in research and in research and innovation policy (Publication of the EU-funded PROSO project, Grant Agreement No. 665947). Accessed 12 January 2021. www.proso-project.eu/proso-support-tool-2018.pdf.

European Commission (2013) Special Eurobarometer 401: Responsible research and innovation (RRI), science and technology. Accessed 30 June 2021. www.genderportal.eu/sites/default/files/ resource_pool/ebs_401_en.pdf.

Irwin, A. (2014) 'Risk, science and public communication: Third-order thinking about scientific culture'. In M. Bucchi and B. Trench (eds), Routledge Handbook of Public Communication of Science and Technology, 2nd ed. London: Routledge, 160-72.

Kahane, D., Loptson, K., Herriman, J. and Hardy, M. (2013) 'Stakeholder and citizen roles in public deliberation'. Journal of Public Deliberation, 9 (2), 1-35. https://doi.org/10.16997/jdd.164.

Kasperowski, D. and Kullenberg, C. (2019) 'The many modes of citizen science'. Science \& Technology Studies, 3 (2), 2-7. https://doi.org/10.23987/sts.74404.

Kleinman, D.L., Delborne, J.A. and Anderson, A.A. (2011) 'Engaging citizens: The high cost of citizen participation in high technology'. Public Understanding of Science, 20 (2), 221-40. Accessed 12 January 2021. http://citeseerx.ist.psu.edu/viewdoc/ download?doi=10.1.1.973.1867\&rep=rep1\&type=pdf

Kosow, H., Dreyer, M., Bauer, A. and Chonkova, B. (2016) Methodology Citizen Panels (Deliverable 4.1 of the EU-funded PROSO project, Grant Agreement No. 665947). Accessed 12 January 2021. www.proso-project.eu/wp-content/uploads/proso_d4.1_methodology_citizen_ panels.pdf.

Kuhlmann, S., Edler, J., Ordóñez-Matamoros, G., Randles, S., Walhout, B., Gough, C. and Lindner, R. (2015) Responsibility Navigator. Karlsruhe: Fraunhofer Institute for Systems and Innovation Research ISI. Accessed 12 January 2021. http://responsibility-navigator.eu/wp-content/ uploads/2016/01/Res-AGorA_Responsibility_Navigator.pdf.

Lidskog, R. (2008) 'Scientised citizens and democratised science: Re-assessing the expert-lay divide'. Journal of Risk Research, 11 (1-2), 69-86. https://doi.org/10.1080/13669870701521636.

Owen, R. and Pansera, M. (2019) 'Responsible innovation and responsible research and innovation'. In D. Simon, S. Kuhlmann, J. Stamm and W. Canzler (eds), Handbook on Science and Public Policy. Cheltenham: Edward Elgar, 26-48.

Powell, M., Colin, M., Kleinman, D., Delborne, J. and Anderson, A. (2011) 'Imagining ordinary citizens? Conceptualized and actual participants for deliberations on emerging technologies'. Science as Culture, 20 (1), 37-70. https://doi.org/10.1080/09505430903567741.

Rask, M., Mačiukaite-Žviniene, S., Tauginiene, L., Dikčius, V., Matschoss, K., Aarrevaara, T. and d'Andrea, L. (2018) Public Participation, Science and Society: Tools for dynamic and responsible governance of research and innovation. London: Routledge.

Reed, M.S., Duncan, S., Manners, P., Pound, D., Armitage, L., Frewer, L., Thorley, C. and Frost, B. (2018) 'A common standard for the evaluation of public engagement with research'. Research for All, (2) 1, 143-62. https://doi.org/10.18546/RFA.02.1.13.

Rowe, G. and Frewer, L.J. (2005) 'A typology of public engagement mechanisms'. Science, Technology, \& Human Values, 30 (2), 251-90. https://doi.org/10.1177/0162243904271724.

Rowe, G., Horlick-Jones, T., Walls, J., Poortinga, W. and Pidgeon, N.F. (2008) 'Analysis of a normative framework for evaluating public engagement exercises: Reliability, validity and limitations'. Public Understanding of Science, 17 (4), 419-41. https://doi.org/10.1177/0963662506075351.

Saldaña, J. (2015) The Coding Manual for Qualitative Researchers. 3rd ed. London: Sage.

Sanders, L.M. (1997) 'Against deliberation'. Political Theory, 25 (3), 347-76. https://doi.org/10.1177/0 090591797025003002.

Schrögel, P. and Kolleck, A. (2019) 'The many faces of participation in science: Literature review and proposal for a three-dimensional framework'. Science \& Technology Studies, 32 (2), 77-99. https://doi.org/10.23987/sts.59519. 
Schütz, R., Hofmaier, C., Saladié, N., Revuelta, G. and Hildt, E. (2015) 'Talking about what? Early engagement activities in the context of neuro-enhancement technologies'. In C. Scherz, T. Michalek, L. Hennen, L. Hebáková, J. Hahn and S.B. Seitz (eds), The Next Horizon of Technology Assessment: Proceedings from the PACITA 2015 Conference in Berlin. Prague: Technology Centre ASCR, 157-61. Accessed 15 July 2020. https://pacita.strast.cz/files/Publikace/ Proceedings-Berlin-v3.2-FINAL_3.pdf.

Stilgoe, J., Lock, S. and Wilsdon, J. (2014) 'Why should we promote public engagement with science?'. Public Understanding of Science, 23 (1), 4-15. https://doi.org/10.1177/0963662513518154.

Strasser, B.J., Baudry, J., Mahr, D., Sanchez, G. and Tancoigne, E. (2019) '“Citizen science"? Rethinking science and public participation'. Science \& Technology Studies, 32 (2), 52-76. https://doi.org/10.23987/sts.60425.

Sturgis, P. (2014) 'On the limits of public engagement for the governance of emerging technologies'. Public Understanding of Science, 23 (1), 38-42. https://doi.org/10.1177/0963662512468657.

Sykes, K. and Macnaghten, P. (2013) 'Responsible innovation - Opening up dialogue and debate'. In R. Owen, J. Bessant and M. Heintz (eds), Responsible Innovation: Managing the responsible emergence of science and innovation in society. Chichester: Wiley, 85-107.

Timotijevic, L. and Raats, M.M. (2007) 'Evaluation of two methods of deliberative participation of older people in food-policy development'. Health Policy, 82 (3), 302-19. https://doi.org/10.1016/ j.healthpol.2006.09.010.

Wilkinson, C., Dawson, E. and Bultitude, K. (2012) "'Younger people have like more of an imagination, no offence": Participant perspectives on public engagement'. International Journal of Science Education, Part B: Communication and public engagement, 2 (1), 43-61. https://doi.org/10.1080/21548455.2011.628503. 